\title{
Análise de nível de eficiência dos portos brasileiros
}

Luciano Ricardo Menegazzo ${ }^{1}$

Arlei Luiz Fachinello ${ }^{2}$

\begin{abstract}
Resumo: O Governo Federal tem realizado ações de retomada do planejamento para o setor portuário nacional por meio da realização de estudos e da elaboração de um novo arcabouço legislativo, institucionalizando o processo de planejamento contínuo ao setor. Este trabalho busca auxiliar o planejamento do setor ao elaborar e analisar a projeção de eficiência dos principais complexos portuários brasileiros até o ano de 2025, identificando oportunidades de planejamento. A metodologia utilizada é a Análise Envoltória de Dados (DEA). Os dados utilizados como insumos e produto são derivados dos Planos Mestres dos portos. Os resultados indicam a ampliação da eficiência média dos portos, enfatizando-se o impacto positivo do número de atracações e o impacto negativo na capacidade ociosa. Junto a isso, observou-se uma redução no número de portos com capacidade insuficiente, indicando que a distribuição de cargas entre os portos deverá ser otimizada.
\end{abstract}

Palavras-chaves: Eficiência dos portos, Planejamento, DEA.

JEL: R42, C14

1 Mestrando em Economia pela Universidade Federal de Santa Catarina. Economista no LabTrans/UFSC. E-mail: lucianormenegazzo@yahoo.com.br

2. Doutor em Economia Aplicada pela Universidade de São Paulo. Professor adjunto no departamento de economia da Universidade Federal de Santa Catarina. E-mail: fachinello@hotmail.com 
MENEGAZZO, L. R.;FACHINELLO, A. L. Análise de nível de eficiência dos portos brasileiros

\section{Efficiency analysis of Brazilian ports}

Abstract:The Federal Government has taken actions to continue the process of planning the port sector, by elaborating studiesand updating its legal framework, institutionalizing the continuous process of the sector's planning. This work aims to assist the planning of the port sector through the analysis of the projection of efficiency of the main Brazilian ports' complexes in the period of 2015-2025. The methodology applied is the Data Envelopment Analysis (DEA). The data of input and output were collected from the Master Plans of the ports. The results indicated and output were collected from the Master Plans of the ports. The results indicated
an increase in the mean efficiency of the ports, highlighting the positive impact of the number of ship arrivals and the negative impact of the idle capacity. Along with that, it was observed a reduction at the number of ports with insufficient capacity, indicating an optimized distribution of cargo between ports.

Keywords: Port Efficiency. Planning. DEA

JEL: R42, C14

\section{Introdução}

O setor portuário tem a função de atuar como uma ligação entre os sistemas de produção e os centros de consumo. Nesse sentido, é o principal elo na cadeia logística do comércio exterior, sendo, portanto, vital para a economia nacional na funcão de garantir o transporte de mercadorias de forma eficaz e eficiente (AKABANE; GONÇALVES 2008). O sistema portuário nacional é composto por 34 portos públicos marítimos e 126 terminais de uso privado - TUPs (BRASIL, 2015b). Em 2014, o setor movimentou cerca de 950 milhões de toneladas, sendo 330 milhões em portos públicos e 620 milhões em TUPs, ou cerca de 65\% do total (ANTAQ, 2015). Em 2013, 94,3\% das mercadorias movimentadas pelo comércio internacional transitaram pelo setor portuário. Atualmente, os portos fluviais e lacustres são de competência do Ministério dos Transportes, enquanto os 34 portos públicos marítimos do Brasil se encontram sob a gestão da Secretaria de Portos da Presidência da República (SEP/PR) (BRASIL, 2015b). Ao analisar a distribuição geográfica da movimentação de cargas no Brasil, observa-se que mais de 50\% do total é transportado por unidades portuárias localizadas na região Sudeste. Como principais fatores para isso, cita-se a presença na região, de sete dentre as dez unidades portuárias de maior movimentação em 2014. Na sequência
MENEGAZZO,R.L.;FACHINELLO,A.L. Análise de nível de eficiência dos portos brasileiros

identifica-se a região Nordeste, com $24 \%$, a região Sul com $15 \%$ e por fim, a região Norte, com 9\% (ANTAQ, 2015).

Analisando o histórico de movimentação de cargas, evidencia-se que desde 2002 a maior quantidade de cargas é transportadapor TUPs, sendo que do total de cargas transportadas pelo setor portuário nacional, a participação dos portos públicos permaneceu no intervalo entre 30\% e 40\%.É importante ressaltar que a movimentação de cargas realizada por TUPs é em grande parte feita em terminais de propriedade de empresas nacionais como Vale S.A. e Petrobras S.A., que os utilizam exclusivamente para o transporte de Petróleo e seus derivados (164 milhões de toneladas em 2014) e minério de ferro (295 milhões de toneladas em 2014), respectivamente (ANTAQ, 2015).Apesar da Lei $\mathrm{n}^{\circ} 12.815$ de 2013 ter retirado restrições de TUPs na movimentação de cargas de terceiros, ainda em 2014, 92\% do volume movimentado nestes termi nais se refere à carga própria, ou seja, mercadorias produzidas pelamesmas empresas proprietárias das unidades portuárias (ANTAQ, 2015). Portanto, o transporte de mercadorias de empresas de menor porte, é quase que inteira mente dependente dos portos públicos. Esses aspectos ressaltam a necessidade de incremento do nível de eficiência dos portos públicos brasileiros.Conforme mencionado, em 2013 foi definido um novo marco legal para a regulação do setor, por meio da Lei $n^{0} 12.815$ de 2013 , que possibilitou novas perspectivas de investimentos. Entre esses, está o Programa de Arrendamentos Portuários, inserido no Plano de Investimentos em Logística - PIL Portos - com previsão de $\mathrm{R} \$ 17,2$ bilhões em investimentos até o ano de 2017 (BRASIL, 2015c).

Também devido à aprovação desta Lei, o Governo Federal retomou as autorizações para Terminais de Uso Privado - TUPs, permitindo expansões de unidades portuárias e a criação de novos TUPs, que em conjunto se traduzem em $\mathrm{R} \$ 11$ bilhões de investimentos (BRASIL, 2015d). Além disso, recursos do PAC 1 e 2 foram alocados em estudos, projetos e obras em 23 portos, totalizando um montante superior a R \$2,7 bilhões entre 2011 e 2014, e, R \$ 1,1 bilhões já estão alocados para obras a partir de 2014 (BRASIL, 2015e). Apesar do montante de recursos que já foi alocado no setor por meio de investimentos, o aumento da qualidade da infraestrutura portuária nacional foi baixo, quando comparado com os demais países. Entre os 144 países analisados pelo Fórum Econômico Mundial (WEF, 2014), o Brasil foi classificado na posição 76 quanto a sua infraestrutura, e na posição 122 quanto à qualidade de seus portos. O Gráfico 1 apresenta o histórico das avaliações entre 2010 e 2014. 
MENEGAZZO, L. R.;FACHINELLO, A. L. Análise de nível de eficiência dos portos brasileiros

GRÁFICO 1 - RANKING GLOBAL DE QUALIDADE DE INFRAESTRUTURA E QUALIDADE DOS PORTOS - BRASIL

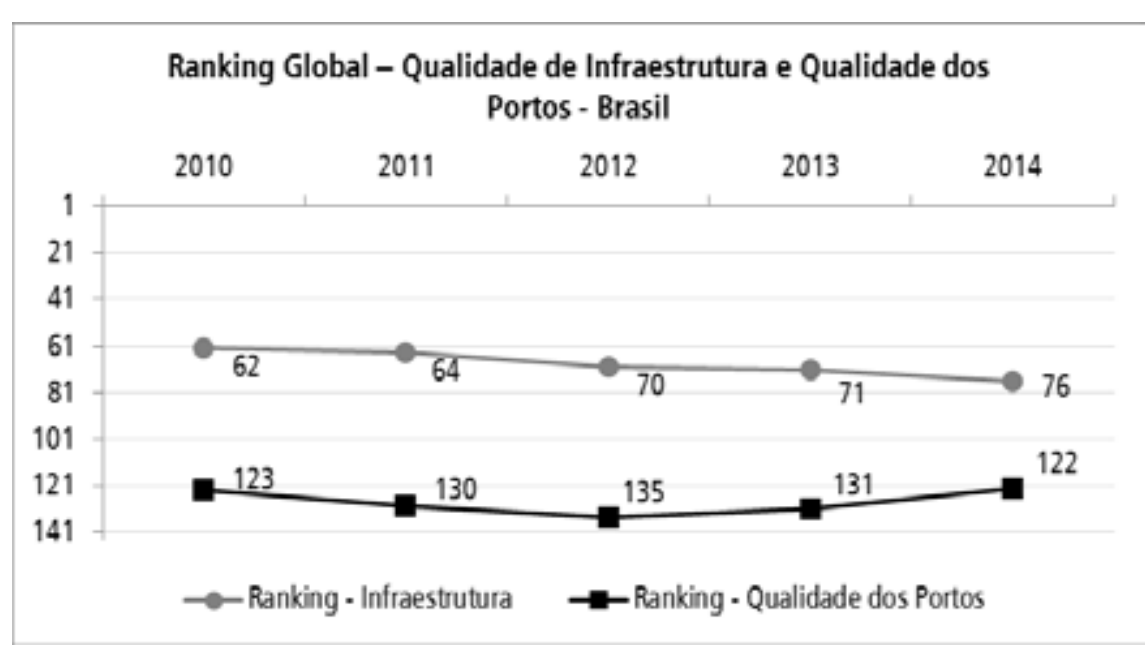

Fonte: Dados - WEF (2014). Elaborado pelos autores.

Conforme indicado pelo gráfico, a qualidade dos portos teve sua pior avaliação em 2012, apresentando melhores resultados a partir desse ano. Uma explicação para o baixo nível de qualidade do setor se refere a ausência de um processo coordenado de planejamento governamental para o setor, restringido pelas políticas adotadas nas décadas de 80 e 90, caracterizado principalmente, pela extinção da Portobras - Empresa de Portos do Brasil S.A. com a Lei ${ }^{\circ}$ 8.029 de 1990. Com a Lei de Modernização dos Portos, Lei nº 8.630 de 1993 , as instalações portuárias foram disponibilizadas ao setor privado por meio de concessões e arrendamentos. Em 2001 foi criada a Agência Nacional de Transportes Aquaviários - ANTAQ, estabelecendo um órgão fiscalizador e regulador para as atividades do setor. Porém, ainda não havia uma entidade responsável pelo planejamento do setor. Diante disso, em 2007 foi criada a Secretaria de Portos da Presidência da República (SEP/PR), possibilitando a retomada do planejamento governamental para o setor. Na sequência, a SEP/PR desenvolveu estudos de auxílio ao planejamento, como o Plano Nacional de Logística Portuária - PNLP e os Planos Mestres dos principais portos nacionais. Estes estudos serviram de base para a elaboração de um novo arcabouço regulatório, resultando na Nova Lei dos Portos, de $\mathrm{n}^{0} 12.815$ de 2013, que alterou as diretrizes de concessão e arrendamento de instalações portuárias, estabelecendo critérios de eficiência e menores tarifas. Além disso, foi publicada a Portaria $\mathrm{n}^{\mathrm{o}} 3$ de 2014 da SEP/PR, que formalizou os instrumentos de planejamento do Governo Federal para o setor portuário. Os instrumentos definidos se referem aos quatro planos, os quais devem ser revisados periodicamente: i) o Plano Nacional de Logística Portuária, ii)

176 Revista de Economia, v. 40, n. 3 (ano 38), p. 173-197, set/dez. 2014. Editora UFPR
MENEGAZZO,R.L.;FACHINELLO,A.L. Análise de nível de eficiência dos portos brasileiros

Planos Mestres, iii) Plano de Desenvolvimento e Zoneamento Portuário e o iv) Plano Geral de Outorgas.

Diante deste cenário, evidencia-se a crescente importância do setor portuário para a economia nacional, e como etapa fundamental para torná-lo mais eficiente, é necessária a realização de estudos de planejamento para auxiliar à tomada de decisão acerca de obras e projetos de investimentos. Este estudo busca identificar o nível de eficiência dos portos nacionais no curto, médio e longo prazo, visando averiguar se a retomada do pla-nejamento governamental para o setor tende a se traduzir na ampliação do nível de eficiência dos portos, comparando-se a situação atual. Como hipótese inicial, espera-se uma elevação dos níveis de eficiência do setor, principalmente em portos queatualmente se evidenciam gargalos e baixos níveis de eficiência.O método a ser utilizado é de Análise Envoltória de Dados - DEA, que permite a comparação do desempenho das unidades portuárias com padrões técnicos. Observa-se diversos trabalhosna literatura analisando a eficiência dos portos, com destaque para:

- Fontes (2006) - Realizou uma análise com três modelos DEA. O primeiro, a que se refere o objetivo do presente estudo, envolveu 31 instalações portuárias no período de 2002 a 2004, considerando como insumo a extensão total de cais, e como produtos, o número de atracações e a movimentação total de cargas. Como principal resultado, identificou que o porto de Areia Branca foi o de maior eficiência.

- Souza et al. (2007) - Utilizou o método de Componentes Principais para reduzir um total de 29 para 4 variáveis para utilizá-las no modelo DEA. Com isso, buscou hierarquizar 29 portos brasileiros com dados de demanda projetada para 2011.

- Sousa Junior et al. (2008) - Analisou os portos do nordeste com orientação a inputs com dados do ano de 2006, considerando dois inputs (comprimento dos berços e calado admissível) e um output (movimentação de cargas). A amostra contou com 22 instalações portuárias e concluiu que a maioria das instalações encontra-se com subaproveitamento da infraestrutura.

- Silva et al. (2011) - Utiliza a metodologia DEA e o Índice Malmquist para avaliar a eficiência de 18 portos entre os anos de 1999 e 2000. O estudo buscou identificar os retornos em escala por meio do teste de Wald para a posterior elaboração do modelo DEA. O estudo indica a necessidade de utilizar um período maior para a avaliação de inovação tecnológica nos portos.

- Acosta et al. (2011) - Analisou 27 instalações portuárias com base em dados de 2005, utilizando como insumo a extensão de cais, profundidade do canal e área de armazenagem, e como produto, movimentação total de cargas. Entre as conclusões, observou que apenas um dos cinco portos

Revista de Economia, v. 40, n. 3 (ano 38), p. 173-197, set/dez. 2014. Editora UFPR 177 
MENEGAZZO, L. R.;FACHINELLO, A. L. Análise de nível de eficiência dos portos brasileiros

eficientes realizava movimentação de apenas um tipo de carga: Areia Branca, movimentando sal.

- Bertoloto et al. (2011) - Os autores avaliam portos públicos e TUPs com características distintas no período de 2007 a 2009, utilizando um método de homogeneização para compensar as DMUs em desvantagem. A amostra utilizada refere-se a 48 instalações portuárias, sendo os insumos do modelo a extensão total dos berços e o calado máximo permitido, e como produto, o volume total de cargas movimentadas. Como resultado, identificou-se que terminais que movimentam minérios sofreram maior impacto da crise internacional de 2008, quando comparados a terminais que movimentam petróleo.

- Cortez et al. (2013) - O estudo busca avaliar a eficiências de oito autoridades portuárias no desempenho de suas funções, considerando o período de 2007 a 2009. Como insumos foram elencadas as variáveis referentes a número de funcionários, custo operacional e investimento. Como produtos, as variáveis foram total de carga movimentada e faturamento. O estudo apontou que a Companhia Docas do Estado de São Paulo foi a mais eficiente.

- Moura et al. (2014) - O foco do trabalho foi em terminais aquaviários de distribuição de petróleo, avaliando nove terminais por meio de dados mensais de 2013. Foram utilizadas como insumos: Número de rebocadores, comprimento total dos berços, número de técnicos do terminal e capacidade de tancagem. Como produtos foram selecionadas as variáveis de volume de petróleo recebido de navios e volume de petróleo enviado às refinarias.

- Rios et al. (2006) - Mensurou a eficiência de terminais de contêineres do Mercosul durante o período de 2002 a 2004 utilizando cinco insumos e dois produtos. A amostra contou com 15 terminais brasileiros, 6 argentinos e 2 uruguaios. Além disso, utilizou o método de regressão Tobit para verificar as variáveis que mais influenciam a eficiência. Como resultados identificou que a maioria dos terminais eficientes se localizaram no Brasil. Além disso, identificou que a variável de número de equipamentos de pátio não foi significativa estatisticamente na explicação da eficiência apesar de diferir com as entrevistas realizadas.

Dentre a literatura considerada, somente o estudo de Souza et al. (2007) utilizou dados projetados na análise de eficiência, porém, os mesmos se referiam apenas a demanda estimada para o ano de 2011, sendo que as demais variáveis dispunham de dados históricos. Portanto, a exceção deste estudo, identificou-se a inexistência de um estudo de análise de eficiência dos portos nacionais utilizando-se de dados atuais e projetados visando o médio e longo prazo. Desta forma, este trabalho procura contribuir para o planejamento de longo prazo do setor ao mensurar a eficiência dos principais portos nacionais por
MENEGAZZO,R.L.;FACHINELLO,A.L. Análise de nível de eficiência dos portos brasileiros

meio de dados projetados até 2025. Como resultados, busca-se identificar portos que terão seus níveis de eficiência ampliados, bem como, sinalizar regiões com baixos níveis de eficiência que podem ser alvo de políticas públicas, tais como, aumento de capacidade com investimentos públicos por parte da SEP/ PR, autorizações de novos terminais privados (TUPs) por parte da ANTAQ, além de estímulos a uma distribuição de cargas otimizada dentre os portos, por meio de reajustes tarifários realizados periodicamente pela ANTAQ.Este artigo divide-se em quatro seções, incluindo-se este capítulo de contexto geral e revisão da literatura. Na sequência, é apresentada a metodologia utilizada. Em seguida, a terceira seção apresenta os dados coletados e os resultados do estudo. Por fim, a quarta seção apresenta as conclusões e as contribuições obtidas com a elaboração deste trabalho.

\section{Metodologia}

A análise da literatura (ESTACHE et al, 2002; CULLINANE et al, 2006; FALCÃO et al, 2012) que envolve a mensuração da eficiência do setor portuário considera principalmente duas metodologias, o método DEA, que avalia a eficiência relativa dos portos da amostra, e o método de fronteiras estocásticas - SFA (Stochastic Frontier Analysis), a qual considera a eficiência técnica e econômica dos portos. A metodologia de fronteiras estocásticas - SFA é paramétrica e estocástica, sendo que só permite considerar uma variável como produto. Além disso, necessita de uma maior quantidade de observações para que seus parâmetros sejam significantes estatisticamente. Por outro lado, a metodologia DEA, por envolver modelos não paramétricos e determinísticos, é baseada em programação linear, o que permite sua aplicação em amostras menores. Este método permite o cálculo da eficiência considerando múltiplos e produtos simultaneamente. Contudo, os resultados obtidos tem sua interpretação limitada à amostra utilizada no modelo, de forma que, os resultados de diferentes modelos não são comparáveis (FALCÃO et al, 2012). De acordo com Panayides et al. (2009) e Falcão et al. (2012), nos últimos anos, o método de análise envoltória de dados - DEA vem apresentando crescente número de aplicações na avaliação de eficiência de portos em todo o mundo. Entre os principais motivos para a utilização dessa análise, consideram-se os atributos metodológicos inerentes, citados no quadro anterior, considerados adequados para a mensuração da eficiência no complexo ambiente portuário (PANAYIDES, 2009). Considerando as características das diferentes metodologias, o presente estudo propõe-se a utilizar o método DEA na mensuração da eficiência portuária, por possibilitar a inclusão de mais de uma variável como produto, permitir o uso de menor número de observações, além de ser um dos objetivos do trabalho a realização de considerações apenas sobre os portos da amostra. 
MENEGAZZO, L. R.;FACHINELLO, A. L. Análise de nível de eficiência dos portos brasileiros

\subsection{Modelo de Análise Envoltória de Dados - DEA}

O modelo DEA gera da função de produção de fronteira com base nas Decision Makinkg Units - DMUs mais eficientes, neste caso, os complexos portuários em análise. A eficiência de cada DMU é mensurada pela distância desta até a fronteira de produção eficiente (CHARNES et al., 1981). O conceito de eficiência técnica admitido nesta metodologia pode ser definido com critérios apresentados em Pareto (1906), Koopmans (1951) e Cooper et al. (2004), e é descrito segundo Ferreira (2009) como:A completa eficiência (100\%) é atingida por uma DMUo (objetivo) se, e somente se, os desempenhos de outras DMU's do conjunto em análise não demonstram que alguns dos insumos ou produtos da DMUo podem ser melhorados, sem piorar os demais insumos e produtos das demais DMU's. (FERREIRA, 2009, p.62)Por meio desta definição, para o cálculo da razão entre diversos insumos e produtos, a metodologia atribui pesos calculados a estas variáveis através de programação linear. Sendo que, os pesos definidos para cada insumo ou produto, em cada DMU, visam atingir valores de eficiência que sejam os mais favoráveis possíveis a cada DMU. Além disso, o cálculo dos pesos é submetido a restriç̃es que remetem aos tipos de retornos em escala da função de produção das DMUs. A escolha do tipo de retorno em escala se traduz na escolha do modelo DEA a ser calculado. O modelo clássico, denominado CCR, de acordo com o nome dos autores: Charnes, Cooper e Rhodes, pressupõe que as DMU's operam com uma função de produção com retornos constantes em escala, (CHARNES et al., 1978). Por outro lado, o modelo BCC admite retornos variáveis em escala na função de produção das DMU's, pois adota-se a restrição de que a soma dos pesos é igual a um, impondo assim, uma restrição de convexidade na função (FONTES, 2006).Considerando o contexto deste estudo, adota-se a premissa de que portos possam obter economias em escala, e portanto, retornos variáveis em escala na sua função de produção. Assim, o trabalho utiliza o modelo BCC. Além disso, o modelo aplicado considera orientação a produto, pois objetiva-se com isso, identificar a quantidade de produtos a ser ampliada para o alcance da eficiência, neste caso, a ampliação do atendimento aos navios por parte dos complexos portuários brasileiros. A equação (1) expõe o Modelo DEA linearizado adotado neste trabalho.

$$
\begin{gathered}
\operatorname{Max} \theta \\
\text { sujeito a } \\
x_{i o}-\sum_{k=1}^{n} x_{i k} \lambda_{k} \geq 0, i=1, \ldots, r \\
-\theta y_{j o}+\sum_{k=1}^{n} y_{j k} \lambda_{k} \geq 0, j=1, \ldots, s
\end{gathered}
$$

180 Revista de Economia, v. 40, n. 3 (ano 38), p. 173-197, set/dez. 2014. Editora UFPR
MENEGAZZO,R.L.;FACHINELLO,A.L. Análise de nível de eficiência dos portos brasileiros

$$
\begin{array}{r}
\sum_{k=1}^{n} \lambda_{k}=1 \\
\lambda_{k} \geq 0 \quad \forall k
\end{array}
$$

Sendo:

$\theta$ - a medida de eficiência;

$\lambda_{k}-$ os pesos dos insumos e produtos da DMU $k$;

$x_{i k}, y_{j k}-$ insumos $i$ e produtos $j$ da DMU $k$;

$x_{i \mathrm{o}}, y_{j \mathrm{o}}$ - insumos $i$ e produtos $j$ da DMU em análise.

O cálculo do modelo foi realizada por meio do aplicativo livre DEAP - Data Envelopment Analysis Program (COELLI, 2013).A definição das variáveis de insumos e produtos considerou a literatura existente, porém, o número de variáveis foi restrita à disponibilidade daquelas projetadas ao longo do período avaliado, conforme apresentado nos Planos Mestres. Com isso, visando realizar uma projeção da eficiência dos portos, não foi ampliado o número de variáveis pela indisponibilidade de sua projeção na literatura base (BRASIL, 2015). Apesar disso, foi possível utilizar variáveis pouco exploradas na literatura, tal como o nível de serviço prestado pelo porto aos navios. Conforme UNCTAD (1985), o tempo de espera para atracação é um dos principais fatores a serem considerados quando avaliado o nível de serviço de uma unidade portuária, e devem ser refletidos no cálculo de sua capacidade, conforme os utilizados no presente estudo. Não obstante, a consideração da análise do nível de serviço foi inserida no presente estudo por meio da variável dummy definida como insumo "Superutilização da Capacidade". Esta variável binária representa a situação de um complexo portuário operando acima de sua capacidade para uma ou mais naturezas de carga. Vale ressaltar que a capacidade estimada nos Planos Mestres, e utilizada neste estudo, é calculada considerando um determinado nível de serviço, ou seja, utilizando parâmetros recomendados internacionalmente para o tempo médio de espera para atracação. Desta maneira, a movimentação de cargas de um porto pode ultrapassar o valor definido como sua capacidade, porém, ao custo de um aumento do tempo médio de espera para atracar, o que representa a deterioração dos níveis de serviço do complexo portuário. O Quadro 1, a seguir, apresenta as variáveis definidas como insumos e produtos. Ressalta-se que os resultados de eficiência calculados pelo modelo dependem inteiramente das variáveis definidas, 
MENEGAZZO, L. R.;FACHINELLO, A. L. Análise de nível de eficiência dos portos brasileiros

portanto, a seleção de outras variáveis resulta em resultados diferentes de eficiência. Além disso, salienta-se que o número de variáveis selecionado está em alinhamento com a literatura existente, como pode ser observado em: Fontes (2006) - 1 insumo e 2 produtos; Sousa Junior et al. (2008) - 2 insumos e 1 produto; Acosta et al. (2011) - 3 insumos e 1 produto; Bertoloto et al. (2011) - 2 insumos e 1 produto.

\section{QUADRO 1 - VARIÁVEIS DE INSUMO E PRODUTO UTILIZADAS NO MODELO} DEA BCC

\begin{tabular}{|l|l|}
\hline Insumos & Produtos \\
\hline Capacidade em nível de serviço & Movimentação total de cargas \\
\hline Superutilização da capacidade & Número de atracações \\
\hline
\end{tabular}

Fonte: Elaborado pelos Autores.

As variáveis definidas como produtos são comumente utilizadas na literatura (FONTES, 2006; SOUSA JUNIOR et al, 2008; ACOSTA et al, 2011; BERTOLOTO et al, 2011). Ressalta-se a importância de considerar como produto não apenas movimentação de cargas, mas também o número de atracações. Isto porque, portos com características feeder ${ }^{3}$, por possuírem infraestrutura muitas vezes reduzida, não atendem navios de grande porte (LAM et al, 2015). Contudo, este tipo de porto pode ser estratégico para o escoamento e distribuição de cargas locais e regionais, como exemplo, cita-se a unidade portuária de Porto Velho, que realizou quase três mil atracações em 2014. Foi o segundo porto que mais recepcionou navios naquele ano, perdendo apenas para Santos, dentre os complexos portuários analisados, apesar de sua movimentação de cargas ser muito inferior. A variável "número de atracações" não foi apresentada em todos os planos mestres. Para viabilizar a análise, quando indisponível, esta variável foi estimada considerando a movimentação de cargas projetada e o valor de consignação média do ano de 2014. Para identificar a trajetória dos níveis de eficiência dos complexos portuários foi considerada uma DMU para cada porto, a cada ano $(2014,2015$ 2020, 2025). Portanto, cada complexo portuário apresenta quatro valores de eficiência, referentes ao nível de eficiência em cada marco temporal. Com isso, o modelo DEA estima a fronteira eficiente com base nas DMUs mais eficientes identificadas ao longo de todo o período analisado, tornando possível a comparação intertemporal dos complexos portuários.O Quadro 2, a seguir, lista as unidades portuárias consideradas no estudo.

3 Portos alimentadores tem como principal função o transporte cargas regionais a portos concentradore (hubports) ou portos de entrada (gateway port).

182 Revista de Economia, v. 40, n. 3 (ano 38), p. 173-197, set/dez. 2014. Editora UFPR
MENEGAZZO,R.L.;FACHINELLO,A.L. Análise de nível de eficiência dos portos brasileiros

QUADRO 2 - COMPLEXOS PORTUÁRIOS ANALISADOS

\begin{tabular}{|c|}
\hline Complexos Portuários \\
\hline Antonina \\
\hline Aratu \\
\hline Belém \\
\hline Cabedelo \\
\hline Estrela \\
\hline Forno \\
\hline Fortaleza \\
\hline Ilhéus \\
\hline Imbituba \\
\hline Itaguaí \\
\hline Itajaí \\
\hline Itaqui \\
\hline Manaus \\
\hline Paranaguá \\
\hline Pecém \\
\hline Pelotas \\
\hline Porto Alegre \\
\hline Porto Velho \\
\hline Rio de Janeiro \\
\hline Rio Grande \\
\hline Salvador \\
\hline Santana \\
\hline Santarém \\
\hline Santos \\
\hline São Francisco do Sul \\
\hline Suape \\
\hline Vila do Conde \\
\hline Vitória \\
\hline \\
\hline \\
\hline
\end{tabular}

Fonte: Elaborado pelos Autores. 
MENEGAZZO, L. R.;FACHINELLO, A. L. Análise de nível de eficiência dos portos brasileiros

\section{Resultados}

Conforme definido na metodologia, uma variável relevante para o estudo foi a projeção de movimentação das instalações portuárias. Portanto, faz-se necessário uma exposição sobre os métodos e principais características envolvidas. Assim, conforme descrito em Brasil (2015), pode-se definir que as projeções de demanda de cargas apresentadas nos Planos Mestres de cada porto possuem alinhamento com a projeção estabelecida no Plano Nacional de Logística Portuária - PNLP, porém, considerando peculiaridades locais de cada carga em cada porto. $\mathrm{O}$ estudo de demanda realizado teve como primeira etapa a estimação dos fluxos de origem e destino, e posteriormente, a alocação das cargas nos portos. Desta forma, primeiramente foram utilizados modelos econométricos de painel com efeitos fixos, com variáveis explicativas de histórico de movimentação, PIB, taxa de cambio e preço médio das mercadorias, considerando cada par de microrregiões geográficas de origem e destino. As variáveis de PIB e taxas de câmbio tiveram como fonte instituições financeiras internacionais como o FMI e The Economist Intelligence Unit. Após esta primeira etapa, é realizada a alocação nos portos dos diferentes fluxos de movimentação de mercadorias de cada origem e destino. Esta alocação foi realizada considerando a minimização do custo logístico, envolvendo a matriz de custos de transporte da malha logística atual e planejada para o Brasil. Considerando que o estudo de projeção de cargas do PNLP teve como base o ano de $2012^{4}$, deve-se considerar que ocorreram alterações nas expectativas dos agentes econômicos até o período atual (2015). Desta maneira, caso atualizadas as projeções de demanda, e realizado um novo modelo DEA, é possível a ocorrência de resultados diferentes para a eficiências dos portos, principalmente no sentido de um menor aumento de eficiência ao longo do tempo, considerando uma redução no fluxo de comércio internacional. Contudo, considerando que aspectos macroeconômicos tem efeito sistemático na economia, seus efeitos sobre os distintos complexos portuários tende a ser homogêneos, não alterando significativamente os níveis de eficiência relativos dentre as unidades da amostra.Tendo em vista as considerações apresentadas acerca das projeções, o gráfico 2 apresenta de forma consolidada os dados projetados em BRASIL (2015) para os complexos portuários em análise. Os dados de movimentação em 2025 indicam um crescimento superior a 150\% da movimentação de 2014, a uma taxa de crescimento médio de $8,8 \%$ ao ano. A capacidade também apresenta crescimento, reduzindo de 15 para 11 o número de portos com insuficiente capacidade em uma ou mais naturezas de carga. A composição de cargas projetada para o ano de 2025 indica que o granel sólido continuará sendo a carga preponderante, com $59 \%$ do total, seguido de contêineres com $18 \%$, granel líquido com $16 \%$, e por fim, carga geral, com os remanescentes $7 \%$.

$4 \quad$ O estudo de projeção de cargas do PNLP foi utilizado como base para todos os Planos Mestres. Desta forma, considera-se como data base 0 ano de publicacão do primeiro plano mestre, do porto de São Francisco do Sul em 2012.

184 Revista de Economia, v. 40, n. 3 (ano 38), p. 173-197, set/dez. 2014. Editora UFPR
MENEGAZZO,R.L.;FACHINELLO,A.L. Análise de nível de eficiência dos portos brasileiros

GRÁFICO 2 - DADOS PROJETADOS DE MOVIMENTAÇÃO E CAPACIDADE DOS COMPLEXOS PORTUÁRIOS ANALISADOS

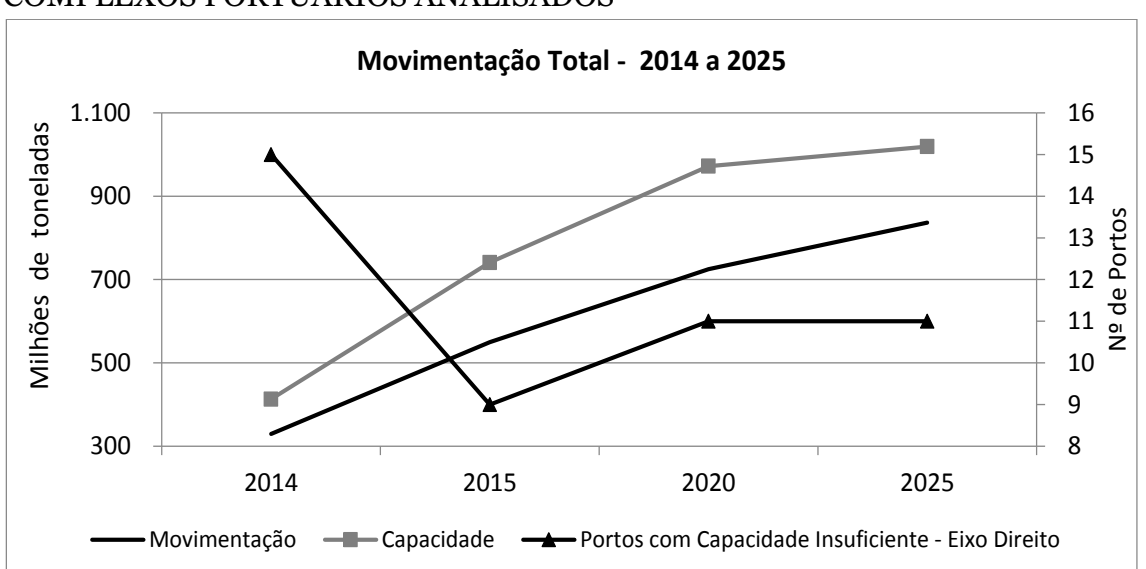

Fonte: Dados dos Planos Mestres (BRASIL, 2015). Elaborado pelos autores.

Comparando os dados projetados para 2025 com os observados em 2014, identifica-se que o maior crescimento da movimentação se refere à carga geral, com crescimento superior a 300\%, em seguida granel líquido, com 170\%, granel sólido, com 160\% e contêineres, com 91\%.

\subsection{Resultados do Modelo DEA}

O Gráfico 3 expõe os 15 complexos portuários que atingiram os maiores valores de eficiência nos anos de 2014 e 2025, respectivamente. Entre os anos avaliados, 2025 foi o que apresentou a maior quantidade de unidades portuárias com a máxima eficiência dentre a amostra considerada, resultado, principalmente, do maior volume de cargas transportadas naquele ano em relação a série histórica 
MENEGAZZO, L. R.;FACHINELLO, A. L. Análise de nível de eficiência dos portos brasileiros

\section{GRÁFICO 3 - UNIDADES DE MAIOR EFICIÊNCIA EM 2014 E 2025}
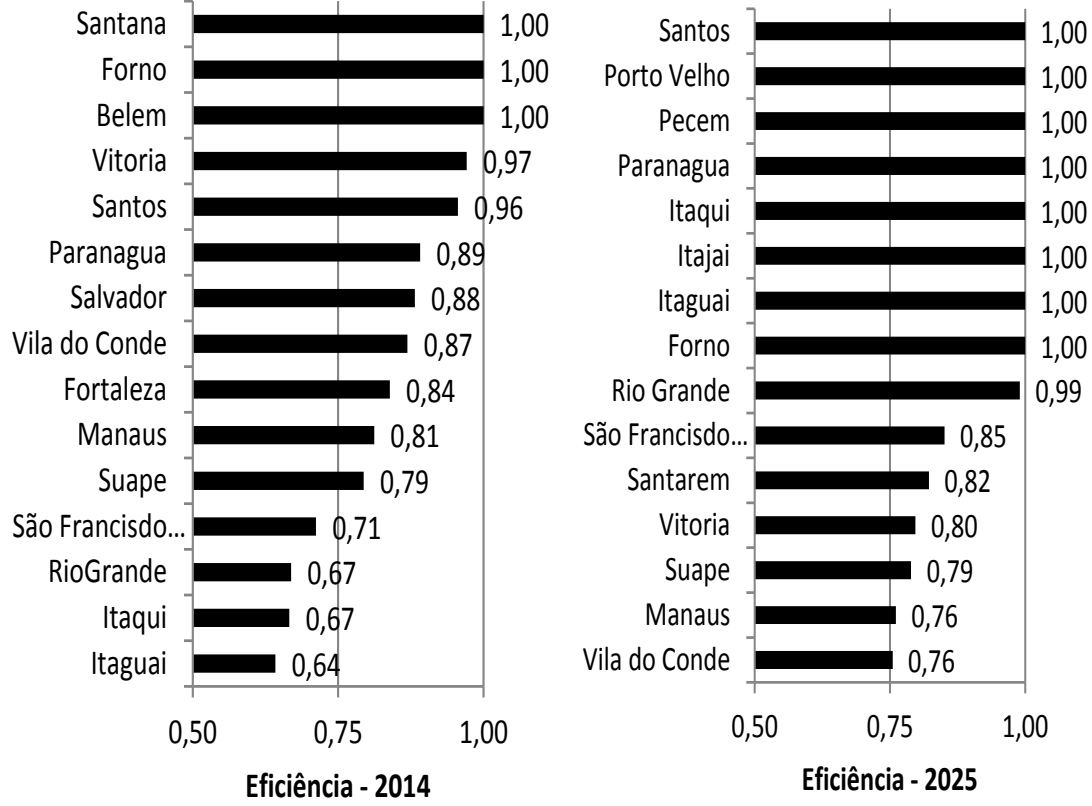

Fonte: Elaborado pelos autores.

Apenas o porto de Forno, identificado como plenamente eficiente em 2014 manteve esta posição no ano de 2025. Portos que eram inicialmente $100 \%$ eficientes e tiveram sua eficiência reduzida ao longo do tempo, dentre outros eficientes e tiveram sua eficiencia reduzida ao longo do tempo, dentre outros fatores, têm planejados investimentos em obras e equipamentos que irão elevar a sua capacidade. Pelo fato de a capacidade ser ampliada em degraus, de forma descontínua, a redução da eficiência deve ocorrer em função da movimentação não crescer na mesma magnitude da ampliação da capacidade. Portanto, o porto deve apresentar capacidade ociosa nos períodos logo após as expansões de capacidade.Verifica-se que porto de maior movimentação, como Santos, Paranaguá, Itaqui e Rio Grande atingiram valores iguais ou próximos a $100 \%$ da eficiência, dentre a amostra. Isso pode confirmar a premissa adotada na escolha do modelo DEA, que permite retornos variáveis em escala, significando que portos com maiores movimentações tendem a apresentar ganhos de eficiência superior a portos com menores movimentações. Contudo, identifica-se que não apenas portos de grande porte atingiram a plena eficiência, como é o caso de Porto Velho, Forno e Pecém. Isso indica que apesar de um menor ganho de eficiência relacionado a escala, estes portos atingiram maiores eficiências técnicas, conforme conceito da própria metodologia DEA. Em outras palavras, estas unidades portuárias de menor porte, em 2025 tendem a otimizar a utilização da infraestrutura disponível, ampliando a relação entre produtos e insumos, sem atingirem um ponto de superutilização de capacidade, o que reduziria a qualidade do serviço prestado

186 Revista de Economia, v. 40, n. 3 (ano 38), p. 173-197, set/dez. 2014. Editora UFPR
MENEGAZZO,R.L.;FACHINELLO,A.L. Análise de nível de eficiência dos portos brasileiros

pelas unidades portuárias.O Gráfico 4 permite identificar a relação entre os insumos e produtos definidos no modelo. Na metodologia DEA o impacto de cada insumo e produto é definido individualmente para cada DMU analisada, com pesos diferentes para cada DMU. Podem-se observar as variáveis que, na média, foram as mais significativas para o alcance de uma maior eficiência dos complexos portuários considerados.

GRÁFICO 4 - COMPARAÇÕES: EFICIÊNCIA VERSUS MOVIMENTAÇÃO E EFICIÊNCIA VERSUS ATRACAÇÕES
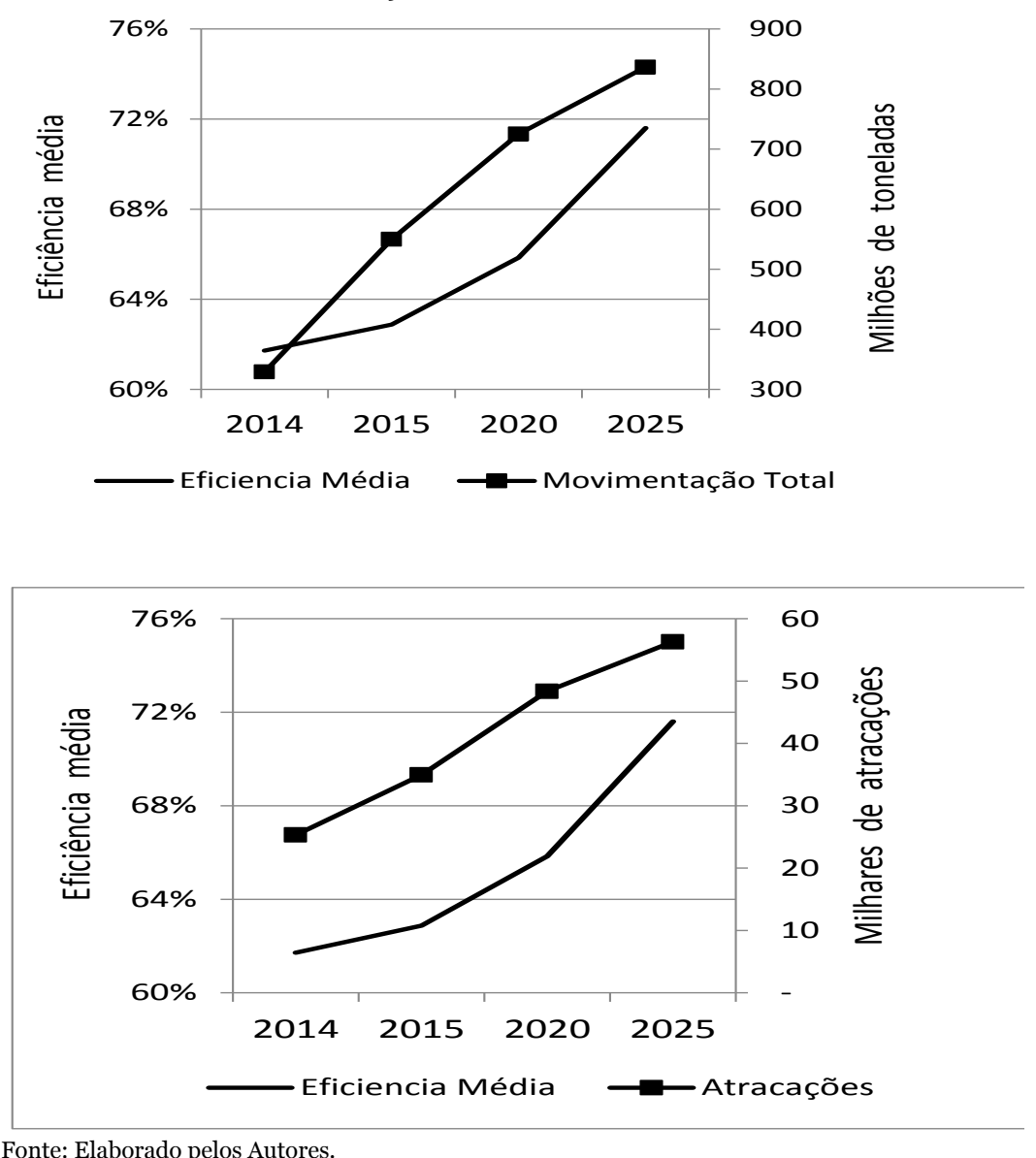

Os resultados indicam que, no período analisado, a maior eficiência esteja relacionada positivamente a maior movimentação, sendo observado que tanto a variável de eficiência média como de movimentação total dos portos apresentaram crescimento ao longo do período. De forma semelhante, o número de atracações também apresentou crescimento no período, influenciando um maior nível de eficiência das unidades portuárias por se tratar de uma variável

Revista de Economia, v. 40, n. 3 (ano 38), p. 173-197, set/dez. 2014. Editora UFPR 187 
MENEGAZZO, L. R.;FACHINELLO, A. L. Análise de nível de eficiência dos portos brasileiros

inserida como produto, no modelo.

GRÁFICO 5 - COMPARAÇÕES: EFICIÊNCIA VERSUS CAPACIDADE TOTAL OCIOSA E EFICIÊNCIA VERSUS NÚMERO DE PORTOS COM CAPACIDADE INSUFICIENTE
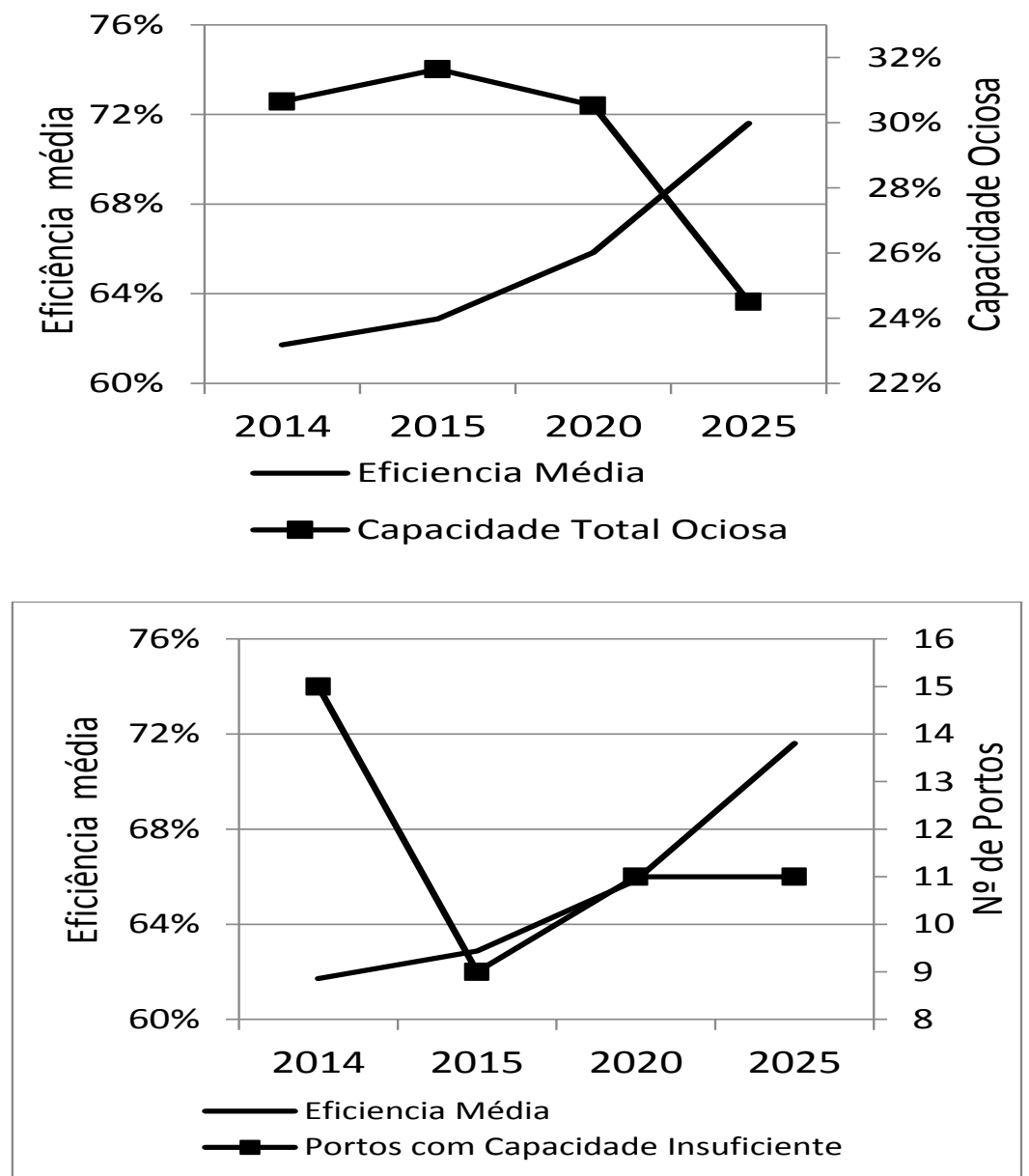

Fonte: Elaborado pelos Autores.

De maneira oposta, a quantidade de portos com capacidade insuficiente apresentou uma relação negativa com a eficiência nos anos de 2014 e 2015, conforme observado no Gráfico 5, possivelmente devido a maior quantidade de portos com capacidade insuficiente nesse período, associada a uma maior quantidade de capacidade ociosa, em termos gerais. Isso representa um cenário de má alocação das cargas nos portos, pois, apesar da existência de capa-

188 Revista de Economia, v. 40, n. 3 (ano 38), p. 173-197, set/dez. 2014. Editora UFPR
MENEGAZZO,R.L.;FACHINELLO,A.L. Análise de nível de eficiência dos portos brasileiros

cidade ociosa em alguns portos, outros se encontravam com superutilização de sua capacidade. À medida que a capacidade ociosa decresceu, o número de portos com capacidade insuficiente passou a apresentar uma relação positiva com a eficiência. Um dos motivos refere-se ao fato de que portos com capacidade insuficiente apresentam altos índices de movimentação de cargas para sua capacidade, que no presente modelo correlaciona-se com os níveis de eficiência pelo fato de um dos insumos ser capacidade e um dos produtos ser movimentação. Além disso, este cenário pode representar que a alocação de cargas nos portos foi otimizada a partir de 2015, reduzindo a capacidade ociosa, em termos gerais.

Ao analisar a capacidade ociosa, identifica-se uma relação inversamente proporcional à eficiência a partir do ano de 2015. Isto pode ser observado pela inclinação dos segmentos de reta de ambas as variáveis. Com base nesta inspeção visual é possível inferir que, dentre as variáveis consideradas no modelo, a capacidade ociosa é a de maior impacto negativo na eficiência.

Ressalta-se que apesar disso, é prudente realizar um planejamento que pos sibilite folgas de capacidade para o atendimento da demanda em períodos de pico, de forma a não prejudicar a operação portuária, o que levaria a congestionamentos no porto, redução de produtividade, e por fim, a redução da própria capacidade de atendimento, incorrendo em maiores filas de espera para atracação. Face à importância da variável de capacidade ociosa, o Gráfico 6 , a seguir, apresenta em qual natureza de carga é evidenciada maior nível de ociosidade, possibilitando indicar possíveis superdimensionamentos de estrutura, e, portanto, possíveis fontes de ineficiência.

GRÁFICO 6 - CAPACIDADE OCIOSA PROJETADA POR NATUREZA DE CARGA

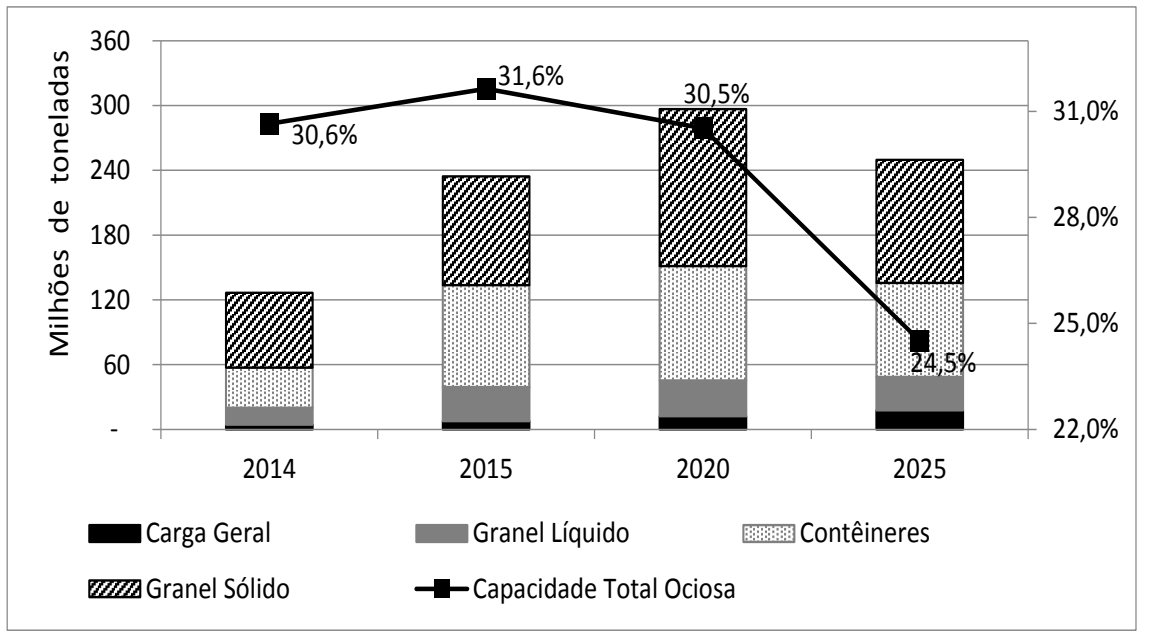

Fonte: Elaborado pelos Autores. 
MENEGAZZO, L. R.;FACHINELLO, A. L. Análise de nível de eficiência dos portos brasileiros

Assim como o montante de movimentação de cargas, a capacidade ociosa é majoritariamente referente a granel sólido. Ao avaliar a capacidade ociosa total disponível nos complexos portuários, identifica-se uma menor utilização da capacidade nos anos de 2014 a 2020, se situando em torno de 30\% da capacidade total. No ano de 2025, a utilização da capacidade esperada é mais elevada, resultando em uma folga menor, no valor de $24,5 \%$ na capacidade total. O nível de utilização da capacidade é um dos principais fatores envolvidos na aferição da eficiência das unidades portuárias, portanto, esses dados reforçam os resultados do modelo DEA, que indicam maior eficiência em 2025 do que nos anos anteriores, principalmente, devido a um menor descompasso entre demanda e capacidade.O Gráfico 7 apresenta os níveis de eficiência por regiões geográficas. Nele, observa-se que os complexos portuários das regiões sudeste e nordeste permanecem acima da média nacional ao longo da maior parte do período. Em contrapartida, as regiões sul e norte se encontram abaixo da mesma, resultado, principalmente do menor número de atracações nestes portos e do maior número de portos com uma ou mais naturezas de carga com capacidade insuficiente em relação às regiões sudeste $\mathrm{e}$ nordeste.

\section{GRÁFICO 7 - EFICIÊNCIA DOS COMPLEXOS PORTUÁRIOS POR REGIÕES}

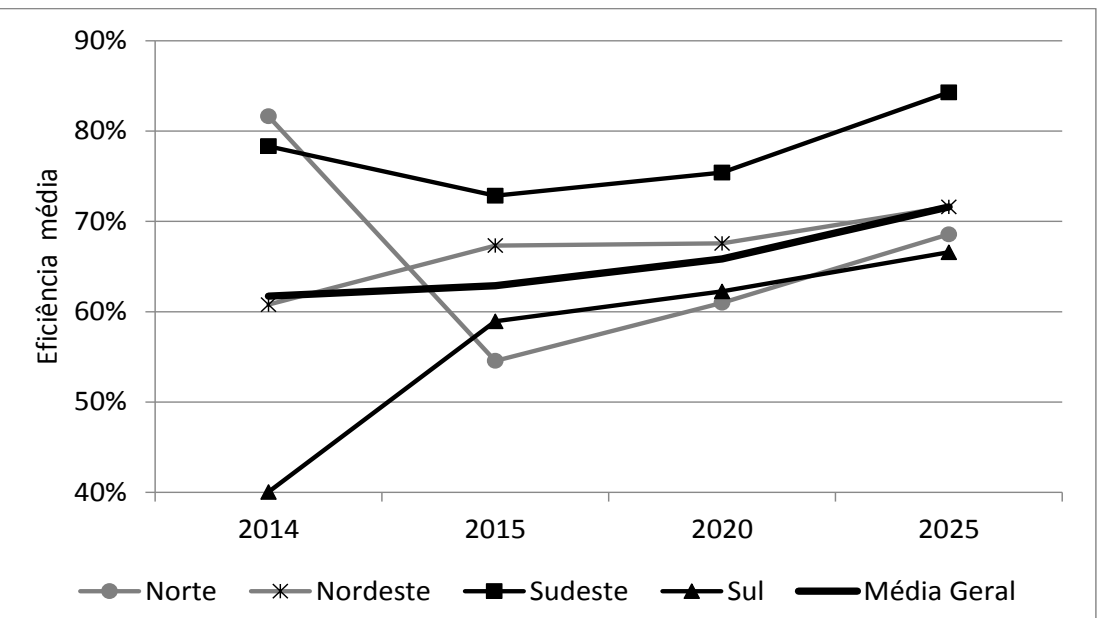

Fonte: Elaborado pelos Autores.

De maneira geral, observa-se que o nível de eficiência projetado tende a ser maior ao longo do tempo, saindo do valor médio nacional de $62 \%$ em 2014, para 72\% em 2025. Apesar do significativo crescimento na movimentação de cargas, projeta-se, paralelamente, uma ampliação da capacidade que pretende se adequar a demanda de maneira mais estreita, se realizadas as obras de ampliação planejadas nos Planos Mestres. Como

190 Revista de Economia, v. 40, n. 3 (ano 38), p. 173-197, set/dez. 2014. Editora UFPR
MENEGAZZO,R.L.;FACHINELLO,A.L. Análise de nível de eficiência dos portos brasileiros

resultado, reduz-se o número de portos com insuficiente capacidade para uma ou mais naturezas de carga, e em conjunto, espera-se a redução de capacidade ociosa, onde atualmente existem. Diante desses resultados, é possível inferir que, se os cenários projetados se concretizarem nos períodos futuros, e em conjunto, as obras de ampliação de capacidade e a retomada do planejamento governamental para o setor tende a se traduzir na ampliação do nível de eficiência dos portos, comparando-se a situação atual.

\section{Conclusão}

O presente estudo teve como objetivo realizar a projeção de eficiência dos principais complexos portuários nacionais por meio da análise envoltória de dados - DEA e dos estudos dos Planos Mestres. Embora o tema já tenha sido analisado por outros autores, não foram encontradas análises de eficiência dos portos brasileiros a partir das novas projeções de demanda e capacidade para os anos de 2020 e 2025. Diante da deficiência de qualidade e da ineficiência operacional observada no setor portuário nacional, quando comparado aos demais países, evidencia-se a necessidade de retomada e expansão do processo de planejamento, possibilitando identificar e sanar gargalos presentes atualmente, bem como os projetados.

Desta maneira, a eficiência dos principais complexos portuários nacionais foi estimada utilizando-se do modelo DEA BCC, que considerou como insumos e produtos as variáveis projetadas para 2015, 2020 e 2025 nos Planos Mestres das unidades portuárias, quais sejam: capacidade em nível de servico e superutilização da capacidade; e, como produtos: movimentação total de cargas e número de atracações.

A coleta dos dados projetados indicou um crescimento superior a 150\% na movimentação total de cargas, considerando o período 2014 a 2025, sendo que as maiores taxas de crescimento estão relacionadas à carga geral e granel líquido, apesar de em termos absolutos estas serem as cargas de menor movimentação. As mercadorias de granel sólido tendem a continuar sendo a maior movimentação do setor, sendo que contêiner, a terceira carga movimentada em 2014, deve passar a ser a segunda mais movimentada em 2025. Tendo em vista o crescimento da movimentação de cargas, a projeção de capacidade indica a redução na capacidade ociosa ao longo do período, possibilitando uma maior aproximação da capacidade e da demanda no ano de 2025, resultando em aumento na eficiência das unidades portuárias.

Entre as principais conclusões do estudo, denota-se a identificação de argu mentos de que a retomada do planejamento governamental para o setor portuário tende a se traduzir na ampliação do nível de eficiência dos portos

Revista de Economia, v. 40, n. 3 (ano 38), p. 173-197, set/dez. 2014. Editora UFPR 191 
MENEGAZZO, L. R.;FACHINELLO, A. L. Análise de nível de eficiência dos portos brasileiros

comparando-se a situação atual. Fornecendo suporte a esta afirmação, cita-se o fato do aumento do número de portos eficientes, dentre a amostra analisada, saindo de três unidades em 2014 para oito unidades em 2025. Além disso, evidencia-se um crescimento da eficiência média desses portos, que saiu de $62 \%$ para $72 \%$. Entre os fatores envolvidos na aferição da eficiência, enfatiza-se o impacto positivo do número de atracações e o impacto negativo na capacidade ociosa. Em 2014 esta variável se encontrava em 30,6\% e em 2025 reduziu a $24,5 \%$, sendo concentrada principalmente nas naturezas de carga de granel sólido e contêiner. Junto a isso, observou-se uma redução no número de portos com capacidade insuficiente, conduzindo a ideia de que, de acordo com o planejamento proposto nos Planos Mestres, a distribuição de cargas entre os portos deverá ser otimizada, de forma a evitar portos com capacidade ociosas ou superutilizações. Com base nisso, aceita-se a hipótese inicial de uma elevação dos níveis de eficiência do setor no médio e longo prazo, com ênfase nos portos de menor eficiência atualmente, referente a região sul, que por excesso de capacidade ociosa em 2014 resultaram na região de menor eficiência. Apesar disso, a medida que amplia-se as exportações e importações, será reduzida a capacidade ociosa, ampliando os níveis de eficiência dos portos da região.

Ressalta-se aqui, a eficiência tratada neste trabalho está vinculada às variáveis definidas no modelo DEA.Os resultados do modelo apontaram para os complexos portuários das regiões sudeste e nordeste como superiores a média nacional, de forma que as regiões norte e sul foram penalizadas pelo menor nú mero de atracações e pelo maior número de portos com capacidade insuficiente para uma ou mais naturezas de carga, quando comparados com as primeiras regiões.

As limitações do estudo estiveram relacionadas principalmente com a coleta de dados, envolvendo tanto variáveis de insumo e produto, como também unidades portuárias avaliadas, ambas restritas às informações disponíveis nos Planos Mestres. Ressalta-se que, apesar de dispor de variáveis projetadas até 2030, o trabalho limitou-se ao estudo até o ano de 2025 com o intuito de incluir o Porto de Santos em todos os períodos, o qual não apresenta capacidade projetada para 2030, apenas demanda de cargas projetadas para o referido ano.

Diante das conclusões apresentadas, evidencia-se a necessidade de aprimorar o planejamento visando adequar a capacidade disponível com a demanda de cargas, sem deixar de considerar folgas de capacidade exigidas para períodos de pico de demanda. Como alternativa, também é possível elaborar programas e políticas de incentivo às unidades portuárias com baixa movimentação de cargas e atracações, possibilitando com isso, além de distribuir de forma mais equitativa as cargas nas diferentes regiões do país, postergar a realização de investimentos em obras de expansão que podem acabar sendo subutilizados.
MENEGAZZO,R.L.;FACHINELLO,A.L. Análise de nível de eficiência dos portos brasileiros

Entre possíveis medidas por parte da ANTAQ, é possível inferir que autorizações de novos TUPs sejam direcionadas a região Sudeste, além de aprimorar a seleção de projetos de novas instalações portuárias privadas na região Sul, que atualmente encontra-se com maior capacidade ociosa em relação as demais regiões. Além disso, a ANTAQ tem a possibilidade de rever medidas de reajuste tarifário, buscando baratear as operações portuárias da região Sul em relação ao Sudeste, visando atrair maior quantidade de cargas, permitindo distribuir de forma mais equitativa o transporte de cargas dentre os portos, maximizando assim a utilização das infraestruturas existentes.

\section{REFERÊNCIAS}

ACOSTA, C. M. M.; SILVA, A. M. V. A.; LIMA, M. L. P. D. (2011). Aplicação de análise envoltória de dados (DEA) para medir eficiência em portos brasileiros. Revista de Literatura dos Transportes. Vol. 5. N. 4.

ANTAQ. Agência Nacional de Transporte Aquaviário (2015). Desempenho Portuário. URL [On Line]: http://www.antaq.gov.br/portal/DesempenhoPortuario/Index. asp. Acesso em: 15 jan. 2015.

AKABANE, G. K; GONÇALVES, M. A. (2008). A importância do modelo de Autoridade Portuária como opção no planejamento logístico. Revista Brasileira de Estratégia, Curitiba, v. 1, n. 1, p. 19-28, jan./abr.

BERTOLOTO, R. F; SOARES DE MELLO, J. C. C. B. (2011). Eficiência de portos e terminais privativos brasileiros com características distintas. Journal of Transport Literature, Vol. 5. N. 2.

BRASIL. Lei no 8.029, de 12 de abril de 1990. Dispõe sobre a extinção e dissolução de entidades da administração Pública Federal, e dá outras providências. Diário Oficial da União, Brasília, DF. Seção 1. 13 abr., 1990. p. 7102.

Lei $\mathrm{n}^{0} 12.815$, de 5 de junho de 2013. Dispõe sobre a exploração direta e indireta pela União de portos e instalações portuárias e sobre as atividades desempenhadas pelos operadores portuários; altera as Leis nos 5.025, de 10 de junho de 1966, 10.233, de 5 de junho de 2001, 10.683, de 28 de maio de 2003 9.719, de 27 de novembro de 1998, e 8.213, de 24 de julho de 1991; revoga as Leis nos 8.630 , de 25 de fevereiro de 1993 , e 11.610 , de 12 de dezembro de 2007 , dispositivos das Leis nos 11.314, de 3 de julho de 2006, e 11.518, de 5 de setemb de 2007; e dá outras providências. Diário Oficial da União, Brasília, DF. Seção 1. Edição Extra. 5 de jun.

.Portaria $\mathrm{n}^{\circ}$ 3, de 7 de janeiro de 2014. Estabelece as diretrizes para a 
MENEGAZZO, L. R.;FACHINELLO, A. L. Análise de nível de eficiência dos portos brasileiros

elaboração e revisão dos instrumentos de planejamento do setor portuário Plano Nacional de Logística Portuária - PNLP e respectivos Planos Mestres, Planos de Desenvolvimento e Zoneamento - PDZ e Plano Geral de Outorgas PGO. Diário Oficial da União, Brasília, DF. Seção 1. Edição 8 de jan.

. Secretaria de Portos da Presidência da República (2015). Planos Mestres URL [On Line]: http://www.portosbrasil.gov.br. Acesso em: 13 de jan. 2015.

. Secretaria de Portos da Presidência da República (2015b). Sistema Por tuário Nacional. URL [On Line]: http://www.portosdobrasil.gov.br/assun tos-1/sistema-portuario-nacional. Acesso em: 15 de jan. 2015.

. Secretaria de Portos da Presidência da República (2015c). Investimentos URL [On Line]: http://www.portosdobrasil.gov.br/assuntos-1/investimentos. Acesso em: 15 de jan. 2015.

. Secretaria de Portos da Presidência da República (2015d). Relação de TUPs autorizados 2013 e 2014. URL [On Line]: http://www.portosdobrasil.gov.br/ assuntos-1/investimentos/itens/attup-atualizado-13-de-janeiro-de-2015.pdf. Acesso em: 15 de jan. 2015 .

. Programa de Aceleração do Crescimento (2015e). Portos. URL [On Line]: http://www.pac.gov.br/transportes/portos/br/. Acesso em: 15 de jan. 2015.

COELLI, T.J; PRASADA R, D.S; BATTESE, G.E. (2013). DEAP Version 2.1. A Data Envelopment Analysis Program. URL [On Line]: http://www.uq.edu.au/economics/cepa/. Acesso em: 22 Maio 2013.

CORTEZ, L. C. S; OLIVEIRA, L. R; MARTINS E.F; JESUS, I. R. D; MELLO, J. C. C. B. S. (2013). Análise de eficiência na gestão de portos públicos brasileiros em relação ao papel das autoridades portuárias. Journal of Transport Literature, vol. 7, n. 2, pp. 78-96.

CULLINANE, K.; WANG, T. F.; SONG, D. W.; JI, P. (2006). The technical efficiency of container ports: comparing data envelopment analysis and stochastic frontier analysis. Transportation Research Part A: Policy and Practice, 40(4), 354374 .

ESTACHE, A.; GONZÁLEZ, M.; TRUJILLO, L. (2002). Efficiency gains from port reform and the potential for yardstick competition: Lessons fromMéxico. World Development 30 (4), 545-560.

FALCÃO, V. A; CORREIA, A. R. (2012). Eficiência portuária: análise das principais metodologias para o caso dos portos brasileiros. Journal of Transport Litera-

194 Revista de Economia, v. 40, n. 3 (ano 38), p. 173-197, set/dez. 2014. Editora UFPR
MENEGAZZO,R.L.;FACHINELLO,A.L. Análise de nível de eficiência dos portos brasileiros

ACOSTA, C. M. M.; SILVA, A. M. V. A.; LIMA, M. L. P. D. (2011). Aplicação de análise envoltória de dados (DEA) para medir eficiência em portos brasileiros. Revista de Literatura dos Transportes. Vol. 5. N. 4.

ANTAQ. Agência Nacional de Transporte Aquaviário (2015). Desempenho Portuário. URL [On Line]: http://www.antaq.gov.br/portal/DesempenhoPortuario/Index. asp. Acesso em: 15 jan. 2015.

AKABANE, G. K; GONÇALVES, M. A. (2008). A importância do modelo de Autoridade Portuária como opção no planejamento logístico. Revista Brasileira de Estratégia, Curitiba, v. 1, n. 1, p. 19-28, jan./abr.

BERTOLOTO, R. F; SOARES DE MELLO, J. C. C. B. (2011). Eficiência de portos e terminais privativos brasileiros com características distintas. Journal of Transport Literature, Vol. 5. N. 2.

BRASIL. Lei no 8.029, de 12 de abril de 1990. Dispõe sobre a extinção e dissolução de entidades da administração Pública Federal, e dá outras providências. Diário Oficial da União, Brasília, DF. Seção 1. 13 abr., 1990. p. 7102.

. Lei $\mathrm{n}^{0} 12.815$, de 5 de junho de 2013. Dispõe sobre a exploração direta e indireta pela União de portos e instalaçỗes portuárias e sobre as atividades desempenhadas pelos operadores portuários; altera as Leis nos 5.025, de 10 de junho de 1966, 10.233, de 5 de junho de 2001, 10.683, de 28 de maio de 2003, 9.719, de 27 de novembro de 1998, e 8.213, de 24 de julho de 1991; revoga as Leis nos 8.630, de 25 de fevereiro de 1993, e 11.610, de 12 de dezembro de 2007, e dispositivos das Leis nos 11.314, de 3 de julho de 2006, e 11.518, de 5 de setembro de 2007; e dá outras providências. Diário Oficial da União, Brasília, DF. Seção 1. Edição Extra. 5 de jun.

.Portaria $\mathrm{n}^{\circ}$ 3, de 7 de janeiro de 2014. Estabelece as diretrizes para a elaboração e revisão dos instrumentos de planejamento do setor portuário Plano Nacional de Logística Portuária - PNLP e respectivos Planos Mestres, Planos de Desenvolvimento e Zoneamento - PDZ e Plano Geral de Outorgas PGO. Diário Oficial da União, Brasília, DF. Seção 1. Edição 8 de jan.

. Secretaria de Portos da Presidência da República (2015). Planos Mestres. URL [On Line]: http://www.portosbrasil.gov.br. Acesso em: 13 de jan. 2015.

. Secretaria de Portos da Presidência da República (2015b). Sistema Por tuário Nacional. URL [On Line]: http://www.portosdobrasil.gov.br/assun tos-1/sistema-portuario-nacional. Acesso em: 15 de jan. 2015.

. Secretaria de Portos da Presidência da República (2015c). Investimentos. URL [On Line]: http://www.portosdobrasil.gov.br/assuntos-1/investimentos.

Revista de Economia, v. 40, n. 3 (ano 38), p. 173-197, set/dez. 2014. Editora UFPR 195 
MENEGAZZO, L. R.;FACHINELLO, A. L. Análise de nível de eficiência dos portos brasileiros

Acesso em: 15 de jan. 2015.

Secretaria de Portos da Presidência da República (2015d). Relação de TUPs autorizados 2013 e 2014. URL [On Line]: http://www.portosdobrasil.gov.br/ assuntos-1/investimentos/itens/attup-atualizado-13-de-janeiro-de-2015.pdf. Acesso em: 15 de jan. 2015.

Programa de Aceleração do Crescimento (2015e). Portos. URL [On Line]: http://www.pac.gov.br/transportes/portos/br/. Acesso em: 15 de jan. 2015.

COELLI, T.J; PRASADA R, D.S; BATTESE, G.E. (2013). DEAP Version 2.1. A Data Envelopment Analysis Program. URL [On Line]: http://www.uq.edu.au/economics/cepa/. Acesso em: 22 Maio 2013.

CORTEZ, L. C. S; OLIVEIRA, L. R; MARTINS E.F; JESUS, I. R. D; MELLO, J. C. C B. S. (2013). Análise de eficiência na gestão de portos públicos brasileiros em relação ao papel das autoridades portuárias. Journal of Transport Literature, vol. 7, n. 2, pp. 78-96.

CULLINANE, K.; WANG, T. F.; SONG, D. W.; JI, P. (2006). The technical efficiency of container ports: comparing data envelopment analysis and stochastic frontier analysis. Transportation Research Part A: Policy and Practice, 40(4), 354374 .

ESTACHE, A.; GONZÁLEZ, M.; TRUJILLO, L. (2002). Efficiency gains from port reform and the potential for yardstick competition: Lessons fromMéxico. World Development 30 (4), 545-560.

FALCÃO, V. A; CORREIA, A. R. (2012). Eficiência portuária: análise das principais metodologias para o caso dos portos brasileiros. Journal of Transport Literature, vol. 6, n. 4, pp. 133-146.

FERREIRA, C. M. C; GOMES, A. P. (2009). Introdução à análise envoltória de dados: teoria, modelos e aplicações. Viçosa. Universidade Federal de Viçosa.

FONTES, O. H. P. M. (2006). Avaliação da eficiência portuária através de uma modelagem DEA. Niterói. Dissertação (Mestrado em Engenharia de Produção) - Programa de Pós-Graduação, Universidade Federal Fluminense.

LAM, L; ISKOUNEN, A. (2015). Feeder ports, Inland ports and Corridors - Time for a closer look. Portek. URL [On Line]: http://www.portek.com/publications/ FeederPort_InlandPortsandCorridors_TimeforaCloserLook.pdf. Acesso em 20 jan. 2015 .

196 Revista de Economia, v. 40, n. 3 (ano 38), p. 173-197, set/dez. 2014. Editora UFPR
MENEGAZZO,R.L.;FACHINELLO,A.L. Análise de nível de eficiência dos portos brasileiros

MOURA, A. L; SANTOS, B. M. F; ANDRADE, E. P. (2014). Modelagem DEA para avaliação de eficiência de terminais aquaviários de transferência e estocagem de petróleo. Relatórios de pesquisa em engenharia de produção. Vol. 14, N. C2.

PANAYIDES, P. M. et al. Routledge Taylor \& Francis Group (2009). Transport Reviews. A Critical Analysis of DEA Applications to Seaport Economic Efficiency Measurement. Vol. 29, No. 2, 183-206, March.

RIOS, L. R.; MACCADA, A. C. G. (2006). Medindo a eficiência relativa das operações dos terminais de contêineres do Mercosul utilizando a técnica de DEA e regressão tobit. Encontro da Associação Nacional de Pós-Graduação e Pesquisa em Administração (EnANPAD), Anais XXV EnANPAD 2006.

SILVA, F. G. F; MARTINS, F. G. D; ROCHA, C. H; ARAÚJO, C. E. F. (2011). Análise exploratória da eficiência produtiva dos portos brasileiros. Transportes, Vol. 19. N. 1.

SPROESSER, R. L; SOGABE, V. P; PEREIRA, A. A; CAMPEÃO, P; MELLO, R. C. (2009). Produtividade em terminais intermodais de grãos: um estudo multicaso utilizando a analise envoltória de dados - DEA. XXIX Encontro Nacional De Engenharia De Produção. Salvador.

SOUSA JUNIOR, J. N. C.; PRATA, B. A.; NOBRE JUNIOR, E. F. (2008). Análise da eficiência dos portos da região nordeste do Brasil baseada em análise envoltória de dados. Sistemas \& Gestão, vol. 3, n. 2, pp. 74-91.

SOUZA, W. F. D. S; SOUZA, G. D. (2007). Infra-estrutura portuária nacional de apoio ao comércio exterior: hierarquização das unidades portuárias. ENGEVISTA, Vol. 9. N. 1.

UNCTAD. United Nations Conference on Trade and Development (1985). Port Development: A handbook for planners in developing countries. United Nations. New York.

WEF. World Economic Forum (2014). The Global Competitiveness Report 20142015. URL [On Line]: http://www3.weforum.org/docs/WEF_GlobalCompetitivenessReport_2014-15.pdf. Acesso em 13 de jan. 2015. 